\title{
Life Events and Postpartum Depression in Tirana, Albania
}

\author{
Daniela Meçe ${ }^{1}$ \\ Aleksander Moisiu University, Durres, Albania \\ E-mail: danielamece@gmail.com
}

\section{Doi: $10.5901 / m j s s .2013 . v 4 n 4 p 311$}

\section{Abstract}

The aim of this study was to explore Post partum Depression (PPD) and the factors that can contribute to PPD, with an emphasis on stressful life events. The study was conducted in Tirana. 398 new mothers from one month postpartum to one year post partum were part of the study. (PPD) and Beck Predictor of Postpartum Depression Inventory (PPDI) are used in this study to evaluate women with PPD and factors contributing to PPD.Approximately $23 \%$ of women that used Edinburg Postpartum Depression Scale resulted with PPD. The study found a weak relationship between Post Partum Depression and stressful life events. Marital problems and death in the family were the main stressful life events related to PPD

Key words: Postpartum Depression, life events, stress

\section{Introduction}

The postpartum period represents one of the most important life stages in which the accurate detection and treatment of psychological distress is required. It involves changes in relationships between couples and within families, and is commonly a cause of additional financial stress, even among households with relatively high incomes. The impact of stressful life events and social health issues on maternal psychological morbidity such as depression, anxiety, and stress has been identified in several studies (Braveman, Yelland, 2010).

Postpartum Depression (PPD) is a depression episode that begins within 6 months after birth and matches the criteria of DSM - IV for major depression without psychotic consequences (APA, 1994). The prevalence of PPD is about $8-35 \%$ depending on the method used for evaluation (Milgrom et al., 2006). PPD occurs when there is an increase in demands on a new mother due to the child development.

Characteristic symptoms of PPD are similar to those of major depression, including sadness, despair, anxiety, compulsive thoughts, and appetite and sleep disturbances. Furthermore, a new mother may have thoughts of harming herself and/or her infant (Taylor 1996; Centers for Disease Control and Prevention 2010). In addition to directly affecting a new mother's mental health, PPD can interfere with a mother's ability to recognize and respond to the needs of her infant, increasing the risk for infant delays in development and behavioral problems in childhood (Horowitz and Goodman 2005). Consequently, PPD is considered a major form of depression that requires treatment and identifying women who may be at an increased risk for developing postpartum depression is crucial. Lack of diagnosis of PPD can affect the mother, her child, family, and society through social dysfunction, illness, and death or treatment costs. (Mrazek \& Haggarty, 1994)

\subsection{Life Events}

Pregnancy and birth are often regarded as stressful life events in their own right, and the stressfulness of these events may lead to depression (Holmes \& Rahe, 1967).

The relationship between life events and the onset of depression is well established (Brown \& Harris, 1978). Experiences such as the death of a loved one, relationship breakdowns or divorce, losing a job or moving home are known to cause stress and can trigger depressive episodes in individuals with no previous history of affective disturbance. However, some researchers have studied the effects of additional stressful life events that women experience during pregnancy and the puerperium. These events, which are thought to reflect additional stress at a time during which women are vulnerable, may play a causal role in postpartum depression.

\footnotetext{
${ }^{1}$ Daniela Mece is a lecturer of Psychology Department, Faculty of Education in Durres University. Any inquires related to this study can be sent to her email address: danielamece@gmail.com 
Paykel et al (1980), using a retrospective design, found that negative life events classified as moderate to severe were associated with increased probability of being diagnosed as clinically depressed.

O'Hara, Rehm and Campbell found that high levels of life events from the beginning of pregnancy until about 11 weeks postpartum were associated with higher levels of depressive symptomatology and a greater likelihood of being diagnosed with postpartum depression (O'Hara, Rehm, \& Campbell, 1982; O'Hara, Rehm, \& Campbell, 1983). Hopkins, Campbell and Marcus (1987) found no association between life events and postpartum depression. At least two other large studies have not found an association between life events and postpartum depression (Holmes et al., 1967; Kumar et al., 1984).

One of the difficulties of assessing a possible relationship between life events and the onset of depression postpartum is the study design. Retrospective collection of data may lead to over reporting of life events as subjects (perhaps subconsciously) try to link a stressful event to a possible cause of the illness. The prospective collection of data eliminates this source of bias, as the outcome of postpartum depression is not known a priori.

In their recent meta-analyses, O'Hara and Swain took values from 15 studies, comprising data on over 1000 subjects that had prospectively recorded data on life events. They found a strong-moderate relationship between experiencing a life event and developing postpartum depression

Beck (2001) used a less rigorously defined measure of 'life stress' to assess studies which measured perceived stress within pregnancy and the early puerperium. She included 16 studies of over 2300 subjects and found a moderate relationship between perceived life stress and postpartum depression. Higher levels of perceived life stress were associated with postpartum depressive symptomatology.

The researchers concluded that life events occurring later in pregnancy were experienced as less distressing to the women. Thus, although there is evidence that distress from life events decreases towards the end of pregnancy, life events that have an impact even during the postnatal period may be more distressing. This is illustrated by Pope (2000) who suggests that life events already distressing during pregnancy can become even more so following childbirth, especially for women who have multiple stressors and limited support.

\subsection{The purpose of the study}

The main purpose of this study was to explore postpartum depression in Tirana and the factors that can contribute to PPD focusing on stressful life events. The results from this study will contribute to a better understanding of this problem. In Albania there is a lack of studies regarding postpartum depression. Better understanding of the problem, factors that affect women's experiences with PPD, will serve for early identification of symptoms and early treatment of mothers, children, and families.

\section{Methodology}

\subsection{Methods}

Edinburgh Postnatal Depression Scale (EPDS) is used for PPD screening. EPDS is one of the best standardized questionnaires used to assess PPD (Cox et al., 1987). Built with 10 self report questions, EPDS has shown high levels of reliability and validity.

The revised version of Beck Postpartum Depression Predictors Inventory (PDPI) was used to elicit information on the risk factors related to PPD. The PDPI is an inventory that evaluates eight risk factors found to be significantly related to postpartum depression; life stress is one of the predictors.

\subsection{Sample}

A sample of 398 women was part of this study. They were all woman one month to one year post partum who attended primary child health centers in Tirana.

\subsection{Procedure and Data Collection}

Study conducted from July to December 2012 in primary child health centers of Tirana. Questionnaires are conducted in private rooms, suitable for the participants and the researcher after the informed consent was taken from participants. 


\subsection{Analysis}

The data were analyzed using the Statistical Package for the Social Sciences (SPSS Version 16.0 for Windows). The data which were collected through the questionnaire were subjected to descriptive statistics

\section{Results}

Table 1 shows the sociodemographic characteristics of the women that were part of the study. Most of them are (60\%) $21-30$ years, $56 \%$ had their first child and $48 \%$ had a university degree.

Table 1 Sociodemographic characteristics of Postpartum mothers

\begin{tabular}{lccc}
\hline & & Frequency & Percent \\
\hline Age & $<20$ years & 29 & 7,3 \\
& $21-30$ years & 242 & 60,8 \\
& $31-40$ years & 118 & 29,6 \\
& $>40$ years & 9 & 2,3 \\
& Total & 398 & 100,0 \\
\hline Postpartum & $<$ one month & 49 & 12,3 \\
period & $1-3$ months & 85 & 21,4 \\
& $3-6$ months & 91 & 22,9 \\
& $6-9$ months & 74 & 18,6 \\
& $9-12$ months & 99 & 24,9 \\
Number of & Total & 398 & 100,0 \\
children & 1 & 223 & 56,0 \\
& 2 & 132 & 33,2 \\
& 3 & 39 & 9,8 \\
& $>3$ & 4 & 1,0 \\
\hline Education & Total & 398 & 100,0 \\
& Basic education & 60 & 15,1 \\
& Secondary school & 145 & 36,4 \\
& University & 192 & 48,2 \\
& Total & & 99,7
\end{tabular}

Table 2 indicates that approximately $23 \%$ of sample women resulted with PPD. These data were collected using the EPDS. In this study EPDS was found to be highly reliable (10 items; $\alpha=.84$ ).

However, a clinical diagnosis is necessary for a clearer assessment of PPD.

Table 2: Postpartum Depression

\begin{tabular}{lcccc}
\hline & Frequency & Percent & Valid Percent & Cumulative Percent \\
\hline No Depression & 305 & 76,6 & 76,6 & 76,6 \\
Depression & 93 & 23,4 & 23,4 & 100,0 \\
Total & 398 & 100,0 & 100,0 & \\
\hline
\end{tabular}


Tables 3 present the relationship between PPD and recently stressful life events. Study participants selected one or more of these stressful life events: Financial problems, marital problems, death in family, serious illness in the family, moving, unemployment and job change.

One of the most stressful life events selected by the participants was financial problems. However results do not indicate any strong relationship between PPD and Financial problems. It was noticed that stressful life events more related with PPD were marital problems and death in the family.

Table 3: Postpartum Depression and Life stress Crosstabulation

\begin{tabular}{|c|c|c|c|c|c|c|c|c|c|}
\hline & & \multicolumn{5}{|c|}{ Life event } & \multirow[b]{2}{*}{$\begin{array}{c}\text { Unemplo } \\
\text { yment }\end{array}$} & \multirow[b]{2}{*}{$\begin{array}{c}\text { Job } \\
\text { change }\end{array}$} & \multirow[b]{2}{*}{ Total } \\
\hline & & $\begin{array}{l}\text { Financial } \\
\text { problems }\end{array}$ & Marital problems & $\begin{array}{l}\text { Death in } \\
\text { family }\end{array}$ & $\begin{array}{c}\text { Serious } \\
\text { illness in } \\
\text { family }\end{array}$ & Moving & & & \\
\hline \multirow{4}{*}{$\begin{array}{l}\text { No } \\
\text { Depres } \\
\text { sion }\end{array}$} & Count & 117 & 101 & 57 & 22 & 6 & 2 & 0 & 305 \\
\hline & $\%$ within $\mathrm{PPM}^{*}$ & $38.4 \%$ & $33.1 \%$ & $18.7 \%$ & $7.2 \%$ & $2.0 \%$ & $.7 \%$ & $.0 \%$ & $100.0 \%$ \\
\hline & $\%$ within Life event & $87.3 \%$ & $80.2 \%$ & $67.1 \%$ & $56.4 \%$ & $54.5 \%$ & $100.0 \%$ & $.0 \%$ & $76.6 \%$ \\
\hline & $\%$ of Total & $29.4 \%$ & $25.4 \%$ & $14.3 \%$ & $5.5 \%$ & $1.5 \%$ & $.5 \%$ & $.0 \%$ & $76.6 \%$ \\
\hline \multirow{4}{*}{$\begin{array}{l}\text { Depres } \\
\text { sion }\end{array}$} & Count & 17 & 25 & 28 & 17 & 5 & 0 & 1 & 93 \\
\hline & \% within PPM & $18.3 \%$ & $26.9 \%$ & $30.1 \%$ & $18.3 \%$ & $5.4 \%$ & $.0 \%$ & $1.1 \%$ & $100.0 \%$ \\
\hline & $\%$ within Life event & $12.7 \%$ & $19.8 \%$ & $32.9 \%$ & $43.6 \%$ & $45.5 \%$ & $.0 \%$ & $100.0 \%$ & $23.4 \%$ \\
\hline & $\%$ of Total & $4.3 \%$ & $6.3 \%$ & $7.0 \%$ & $4.3 \%$ & $1.3 \%$ & $.0 \%$ & $.3 \%$ & $23.4 \%$ \\
\hline \multirow{4}{*}{ Total } & Count & 134 & 126 & 85 & 39 & 11 & 2 & 1 & 398 \\
\hline & \% within PPM & $33.7 \%$ & $31.7 \%$ & $21.4 \%$ & $9.8 \%$ & $2.8 \%$ & $.5 \%$ & $.3 \%$ & $100.0 \%$ \\
\hline & $\%$ within Life event & $100.0 \%$ & $100.0 \%$ & $100.0 \%$ & $100.0 \%$ & $100.0 \%$ & $100.0 \%$ & $100.0 \%$ & $100.0 \%$ \\
\hline & $\%$ of Total & $33.7 \%$ & $31.7 \%$ & $21.4 \%$ & $9.8 \%$ & $2.8 \%$ & $.5 \%$ & $.3 \%$ & $100.0 \%$ \\
\hline
\end{tabular}

* PPM = Postpartum mothers

Pearson correlation is used to evaluate the relationship between Postpartum Depression and stressful life events. As shown in Table 4, Post partum depression and stressful life events were weakly correlated at a significant level; $r(396)=$ $.25, P<.01$.

Table 4: Relationship between Post partum Depression and life events Correlations

\begin{tabular}{llcc}
\hline \hline & & Depression & Life events \\
\hline Depression & Pearson Correlation & 1 & $.249^{*+}$ \\
& Sig. (2-tailed) & & .000 \\
& $\mathrm{~N}$ & 398 & 398 \\
\hline Life events & Pearson Correlation & $.249^{* *}$ & 1 \\
& Sig. (2-tailed) & .000 & \\
& $\mathrm{~N}$ & 398 & 398 \\
\hline \hline
\end{tabular}

${ }^{* \star}$. Correlation is significant at the 0.01 level (2-tailed). 


\section{Discussion}

Having a child is a time of biological, psychological, and social changes in a woman's life. These changes can contribute to personal growth and happiness, but they may also predispose women to emotional distress. This study offers important information about PPD and stressful life events in Tirana.

According to Milgrom et al. the prevalence of PPD is about $8-35 \%$ depending on the method used for evaluation (Milgrom et al., 2006). In the present study 23\% of new mothers resulted in PPD. Results indicate a high prevalence of postpartum depression in Tirana. The lack of studies related to PPD in Albania makes it difficult to have a clear representation of the problem, but it also indicates the desperate need for these studies.

It should be noted that this is only a prediction of the PPD and that a clinical diagnosis is needed for a clearer assessment.

Regarding the relationship between PPD and stressful life events, the results show a weak significant correlation according to Davis (1971), $r=.25$.

Many previous studies show a connection between PPD and stressful life events (O'Hara, Rehm, \& Campbell, 1982; O'Hara, Rehm, \& Campbell, 1983). However there are also studies that do not put much emphasis on stress but rather focus on other factors associated with PPD. Hopkins, Campbell and Marcus (1987), for example, found no association between life events and postpartum depression.

One of the limitations that should be taken into consideration is that there are other sources of stress, not presented in this paper, that can contribute to PPD.

One of the most stressful life events selected by the participants was financial problems. Having a child involves changes in relationships between couples and within families, and it is commonly a cause of additional financial stress, even among households with relatively high incomes. This may also reflect the economic crisis that has involved all the region. However results do not indicate any strong relationship between PPD and Financial problems. It was noticed that stressful life events more related to PPD were marital problems and death in the family.

The current study results make us believe that the provision of adequate postpartum care is crucial in the identification of emotional distress. Considering the high prevalence of PPD during the mothers' postpartum period, this kind of studies are crucial for early identification of symptoms and early treatment of mothers, children, and families.

\section{References}

APA, Diagnostic and Statistical Manual of Mental Disorders (4th edn). American Psychiatric Association, Washington, D.C.,1994,

Beck, C. T. (2001). Predictors of postpartum depression: an update. Nursing Research, 50, 275-285.

Boyce, P., A. Hickey, J. Gilchrist, and N.J. Talley. 2001. "The Development of a Brief Predictive Index for the Detection of Women at Risk for Postnatal Depression." Birth.

Taylor, Verta. 1996

Braveman P, Marchi K, Egerter S, et al. Poverty, near poverty, and hardship around the time of pregnancy. Matern Child Health J. 2010;14(1):20-35.

Brown, G. W. \& Harris, T. (1978). Social Origins of Depression: A Study of Psychiatric Disorder in Women. New York: The Free Press.

Centers for Disease Control and Prevention. 2010. "Depression Among Women of Reproductive Age and Postpartum Depression." Retrieved May 1, 2011 (HYPERLINK"http://www.cdc.gov/reproductivehealth/Depression/"). 30(2):101-08.

Cox JL, Holden JM, Sagovsky R. Detection of postnatal depression: Development of the 10-item Edinburgh Postnatal Depression Scale. Journal of Psychiatry. 1987;150:782-786

Davis, J. A. (1971). Elementary survey analysis.Englewood Cliffs, NJ: Prentice-Hall.

Holmes, T. H. \& Rahe, R. H. (1967). The Social Readjustment Rating Scale. Journal of Psychosomatic Research, 11, $213-218$.

Horowitz, June Andrews and Janice H. Goodman. 2005. "Identifying and Treating Postpartum Depression." Journal Of Gynecologic \& Neonatal Nursing. 34(2): 264-73. International Review of Psychiatry, 8, 37-54.

Kumar, R. \& Robson, K. M. (1984). A prospective study of emotional disorders in childbearing women. British Journal of Psychiatry, 144, 35-47. Canberra: NHMRC.

Milgrom, J., Ericksen, J., McCarthy, R., \& Gemmill, A. (2006). Stressful impact of depression on early mother-infant relations. Stress \& Health: Journal of the International Society for the Investigation of Stress, 22(4), 229-238

Mrazek PJ, Haggarty RJ, Reducing risks for mental disorders: frontiers for preventive intervention research. IOM, The National Academy of Sciences, United States of America,1994

O'Hara, M.W., \& Swain, A.M. (1996). Rates and risk of postpartum depression: A meta-analysis.

International Review of Psychiatry, 8, 37-58.

O'Hara, M. W., Rehm, L. P., \& Campbell, S. B. (1982). Predicting depressive symptomatology: cognitive behavioral models and postpartum depression. Journal of Abnormal Psychology, 91, 457-461. 
O'Hara, M. W., Rehm, L. P., \& Campbell, S. B. (1983). Postpartum depression. A role for social network Hopkins, J., Campbell, S. B., \& Marcus, M. (1987). Role of infant-related stressors in postpartum depression. Journal of Abnormal Psychology, 96, $237-241$.

Paykel, E. S., Emms, E. M., Fletcher, J., \& Rassaby, E. S. (1980). Life events and social support in puerperal depression. British Journal of Psychiatry, 136, 339-346.

Pope, S 2000, Postnatal Depression: A Systematic Review of Published Scientific Literature to 1999: An Information Paper. National Health and Medical Research Council, Canberra.

Webster, Joan, Margo A. Pritchard, Debra Creedy, and Chris East. 2003. "A Simplified Personality Scale to Measure Vulnerability to Postnatal Depression." Archives of Women's Mental Health. 3:147-53.

Yelland J, Sutherland G, Brown SJ. Postpartum anxiety, depression and social health: findings from a population-based survey of Australian women. BMC Public Health. 2010;10:771. 